\title{
Knowledge, Attitude and Practice on Smoking Cessation Guideline among Medical Doctors attending Family Medicine Scientific Conference 2016
}

Mohd Shaiful Ehsan Bin Shalihin ${ }^{1}$, Mohd Aznan Md Aris ${ }^{1}$, Mohamad Haniki Nik Mohamed $^{2}$, Razman Bin Mohd Rus ${ }^{3}$, Nurjasmine Aida Bt Jamani ${ }^{1}$ ${ }^{1}$ Department of Family Medicine, Kulliyyah of Medicine, International Islamic University Malaysia

${ }^{2}$ Kulliyyah of Pharmacy, International Islamic University Malaysia

${ }^{3}$ Department of Community Medicine, Kulliyyah of Medicine, International Islamic University Malaysia

Presenter: Mohd Shaiful Ehsan Bin Shalihin

Introduction: Prevalence of active smokers in Malaysia remains high despite the availability of stop-smoking services. Rather than focussing on patients' demotivating factors, possible poor performance from providers should be evaluated. Thus, knowledge, attitude and practice of the healthcare professional on smoking cessation intervention needs to be assessed, especially among primary care doctors. Materials and Methods: A cross-sectional study was conducted among primary care medical doctors attending the $19^{\text {th }}$ Family Medicine Scientific Conference 2016 held at the Grand Dorsett, Subang on the $10^{\text {th }}$ to the $13^{\text {th }}$ August 2016. Validated questionnaire of Knowledge, Attitude and Practice (KAP) of Medical Doctors on Smoking Cessation Guidelines consisting 17 questions were used to determine the KAP score. The difference between the median KAP scores between age, gender, ethnicity, religion, profession, location of clinic, availability of specialist in clinic, numbers of smokers seen and presence of smoking cessation training were assessed using Mann-Whitney $U$ Test and Kruskal Wallis $H$ Test. Results: A total of 145 primary care doctors involved in the study. Majority were female (84.1\%), Malay (73.1\%) and haven't undergone any kind of smoking cessation training (47.6\%). The KAP score were statistically associated with presence of specialist, type of profession, history of attending training program, ethnicity and religion $(\mathrm{p}<0.05)$. Conclusion: Majority of the involved primary care doctors had low KAP score. Being a family medicine specialist, in charge of stop smoking clinic and having attended smoking cessation training program were significantly associated with high KAP score. Therefore, more smoking cessation training should be provided to the primary care doctors. 